\title{
Long non-coding RNA KTN1-AS1 promotes progression in pancreatic cancer through regulating microRNA-23b-3p/high-mobility group box
}

\section{2 axis}

\author{
Zhong-Bo Zhang ${ }^{1}$, Ning Liu $^{1, \&}$ \\ ${ }^{1}$ Department of Pancreatic and Biliary Surgery, The First Affiliated Hospital of China Medical University, Shenyang \\ 110001, Liaoning Province, China
}

Correspondence to: Ning Liu; email: ningtaodun6035@163.com, https://orcid.org/0000-0001-7472-6777

Keywords: IncRNA KTN1-AS1, miR-23b-5p, HMGB2, pancreatic cancer, proliferation, invasion

Received: April 13, 2021

Accepted: July 30, 2021

Published: August 30, 2021

Copyright: (c) 2021 Zhang and Liu. This is an open access article distributed under the terms of the Creative Commons Attribution License (CC BY 3.0), which permits unrestricted use, distribution, and reproduction in any medium, provided the original author and source are credited.

\section{ABSTRACT}

To explore the inhibitory effect of long non-coding RNA (LncRNA) antisense of KTN1 (KTN1-AS1) on the growth of pancreatic cancer (PC) cells by regulating the microRNA-23b-3p (miR-23b-3p)/high-mobility group box 2 (HMGB2) axis. The expression of KTN1-AS1 in tissues and cells was detected by qRT-PCR, and the relationship between KTN1-AS1 and clinicopathological data of patients with PC was analyzed. In addition, stable and transient overexpression and inhibition vectors were established and transfected into PC cells PANC-1, BxPC-3. CCK-8, transwell, and flow cytometry were responsible for the detection of proliferation, invasion, and apoptosis of transfected cells, respectively. The correlation of miR-23b-3p between KTN1-AS1 and HMGB2 was determined by dual luciferase reports, and the relationship between KTN1-AS1 and miR23b-3p was further verified by RNA immunoprecipitation (RIP). The highly expressed KTN1-AS1 in PC patients was indicative of its high diagnostic value in this disease. Besides, it was found that KTN1-AS1 was linked with the pathological stage, differentiation degree and lymph node metastasis (LNM) of PC patients. Underexpressed KTN1-AS1 led to decreased proliferation and invasion ability of cells and increased apoptosis rate, while the effect of further overexpression of KTN1-AS1 on cells was the opposite. Dual luciferase reporter (DLR) assay confirmed that KTN1-AS1 could target miR-23b-3p, while miR-23b-3p could target HMGB2. Functional analysis showed that the overexpression of miR-23b-3p inhibited the expression of HMGB2 in PC cells and affected cell proliferation, invasion and apoptosis. Co-transfection of Sh-KTN1-AS1 and miR-23b-3p-mimics exhibited that up-regulation of KTN1-AS1 expression could reverse the effect of miR23b-3p-mimics on PC cells.

\section{INTRODUCTION}

Pancreatic cancer (PC) is a leading cause of tumorassociated mortality [1]. Recently, with advancement of medical technology, significant improvement has been indicated for PC treatment, but due to its high malignancy and easy metastasis, its 5-year survival rate is still under $10 \%[2,3]$. The absence of obvious symptoms in the early stage of PC and the limitations of routine physical examination partially underlie the poor prognosis of PC patients, leading to the diagnosis of many $\mathrm{PC}$ patients in advanced stages [4]. Therefore, searching for the possible pathogenesis of PC and its possible therapeutic targets have important clinical significance for patients with PC. Nevertheless, the regulatory mechanism of PC pathogenesis remains elusive.

Long non-coding RNA (LncRNA) is an RNA of more than 200 bases in length that can regulate transcripts by competitive binding with miRNAs, and has been stated in some reports to be effective in human diseases, especially cancer $[5,6]$. For example, it has been 
reported that LncRNA HOTAIR can regulate HER2 through competitive binding with miR-331-3p, and ultimately accelerate the growth and metastasis of gastric cancer cells [7]. Another case is that, LncRNA ZEB2-AS1 influences growth and metastasis of PC by regulating miR-204/HMGB1 axis [8]. In the present study, we performed RNA-seq analysis in clinical PC samples and identified that the antisense of KTN1, RNA1 (KTN1-AS1), significantly elevated in clinical PC samples relative to para-tumor tissues. KTN1-AS1 is the latest LncRNA that has been found to function as a cancer-promoting factor in several cancers [9-10]. However, the effect of KTN1-AS1 on PC progression remains elusive. We found the interaction between miR23b-3p and KTN1-AS1 using bioinformatics analysis. MiR-23b-3p induces suppressive function in various cancers. For instance, by targeting cyclin G1, it can regulate progression of osteosarcoma [11]. However, the relationship of KTN1-AS1 with miR-23b-3p in the modulation of PC development is still obscure.

In the present investigation, we explored function and related mechanisms of KTN1-AS1 in PC. We identified a critical role of KTN1-AS1 in promoting PC by targeting miR-23b-3p/HMGB1 axis.

\section{RESULTS}

\section{High KTN1-AS1 expression in PC}

To identify the potential lncRNAs which were involved in the modulation of PC progression, we performed the RNA-seq analysis in clinical PC tissues and adjacent non-tumor tissues. Among the differently expressed lncRNAs, we identified that KTN1-AS1 presented a most significant elevation in the PC tissues (Figure 1A). We then selected KTN1-AS1 for the further analysis. Moreover, quantitative detection of KTN1-AS1 in PC tissues detected by qRT-PCR exhibited that KTN1-AS1 in PC samples was obviously elevated compared with para-tumor tissues, (Figure 1B), and likewise, KTN1AS1 was observably enhanced in PC cells relative to normal epithelial pancreatic cells. (Figure 1C). The PANC-1 and BxPC-3 cell lines were selected in the subsequent experiments. We demonstrated that the AUC of KTN1-AS1 was 0.946 in the Receiver operating characteristic (ROC) curve (Figure 1D). According to the median expression of KTN1-AS1 (1.68), samples were divided into 48 cases with high KTN1-AS1 expression and 39 cases with low KTN1AS1 expression. It turned out that KTN1-AS1 was
A

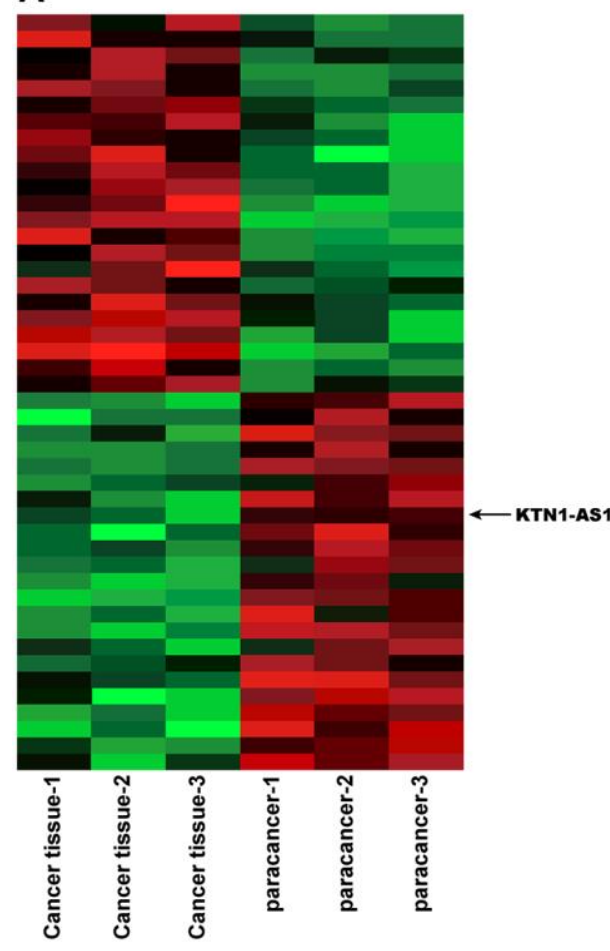

B
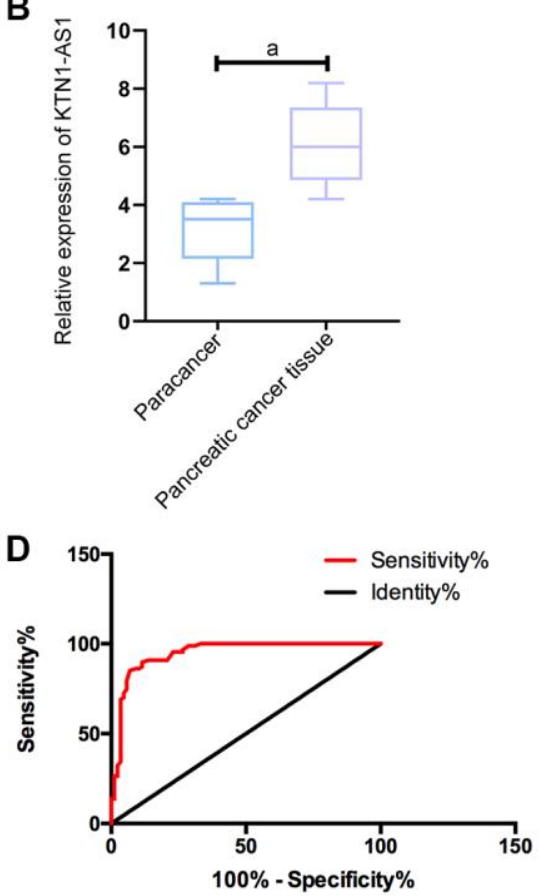

C

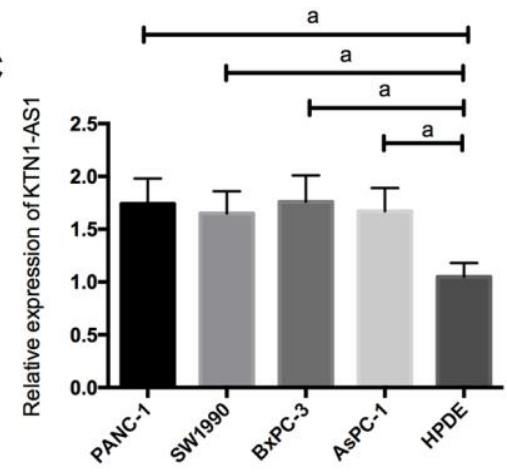

E

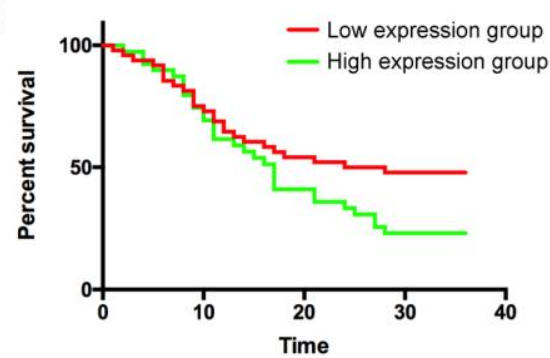

Figure 1. KTN1-AS1 expression and significance in PC. (A) Heatmap of differentially expressed IncRNAs in the RNA-seq analysis of clinical PC tissue and paracancer tissues, fold change $\geq 2$ and $P$ value $<0.05$. (B) KTN1-AS1 expression in PC tissue. (C) KTN1-AS1 expression in pancreatic cancer cells. (D) ROC curve of KTN1-AS1 in the diagnosis of PC. (E) Effects of different KTN1-AS1 expression levels on the survival rate of patients with PC. a indicates $P<0.05$. 
correlated with tumor size, LNM, differentiation degree, and pathological stage. We identified that high KTN1AS1 expression was correlated with the poor survival rate of the PC patients. (Table 1, Figure 1E).

\section{KTN1-AS1 induced oncogenetic function in PC cells}

We transfected Si-KTN1-AS1, sh-KTN1-AS1 and control NC into PANC-1 and BxPC-3 to observe the effect of KTN1-AS1 on PC cells. It was noticed that the KTN1-AS1 expression in Si-KTN1-AS1 group cells was markedly down-regulated but was increased in ShKTN1-AS1 group cells $(P<0.05)$. Knockdown of KTN1-AS1 suppressed the proliferation and invasion of PC cells but accelerated their apoptosis, observably upregulated pro-apoptotic Bax and Caspase-3 expression, and remarkably down-regulated the anti-apoptotic bcl-2 expression $(P<0.05)$. While on the contrary, KTN1-AS1 could further induce the proliferation/invasion and inhibit apoptosis of PC cells, and meanwhile, markedly declined
Bax and Caspase-3 expression, and dramatically enhanced bcl-2 expression. (Figure 2 and Supplementary Figure 1) The expression of Bax, Bcl-2, and caspese- 3 was verified by IHC in the clinical PC tissues and paracancer tissues. (Supplementary Figure 2).

\section{KTN1-AS1 inhibited miR-23b-3p expression by binding to it}

To explore the potential downstream miRNAs of KTN1-AS1, we performed the RNA-seq analysis in PANC-1 cells transfected with sicontrol or siKTN1AS1. Among the differently expressed miRNAs, we identified that miR-23b-3p presented a most significant enhancement by the depletion of KTN1-AS1 in PANC1 cells (Supplementary Figure 3). We then selected miR-23b-3p for the further analysis. Moreover, we found the potential binding target of KTN1-AS1 and miR-23b-3p. To further verify it, we employed DLR and RIP experiments to confirm their correlation.
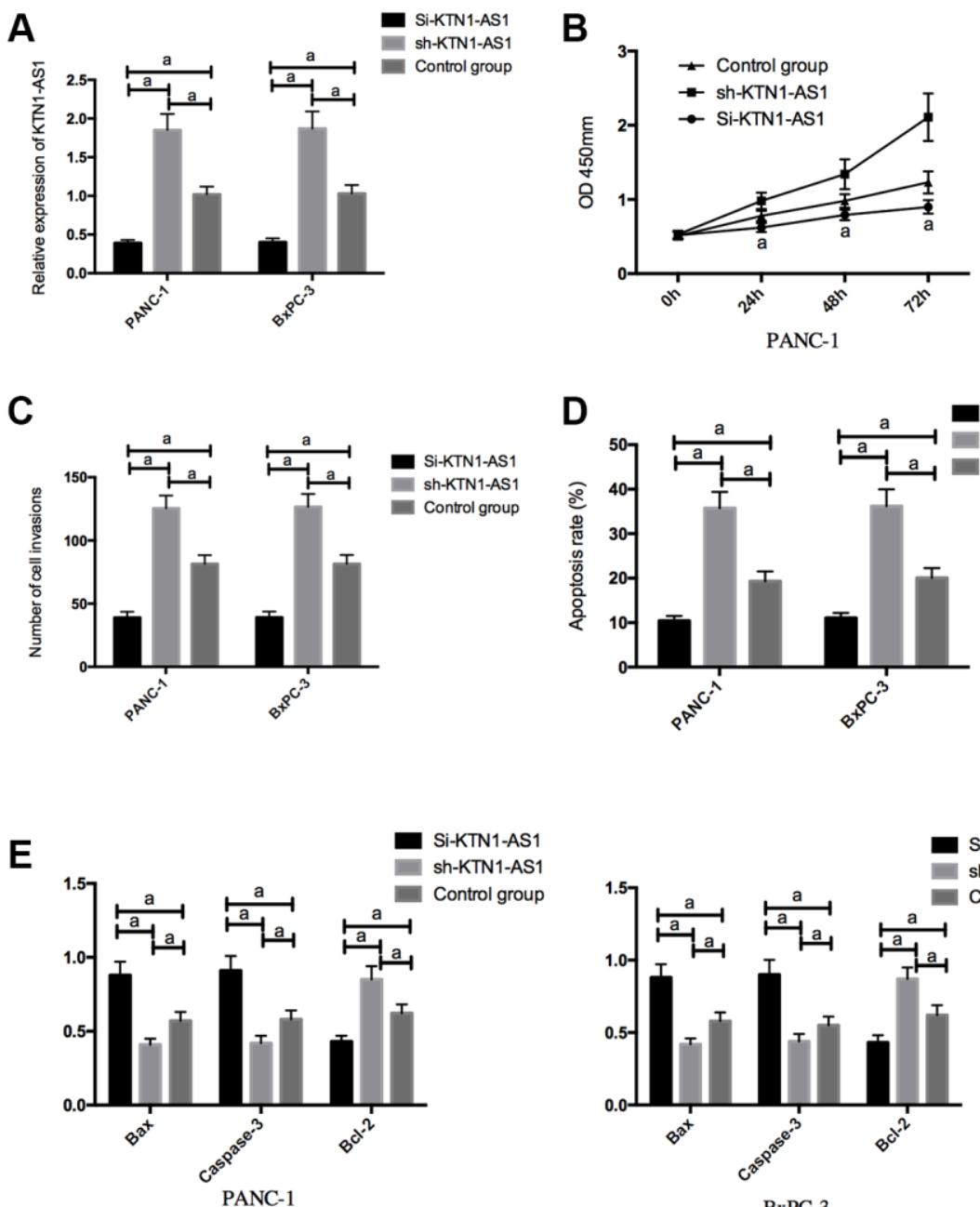

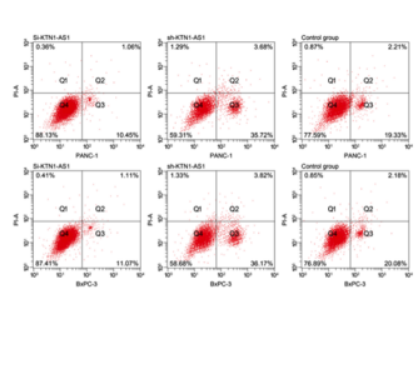

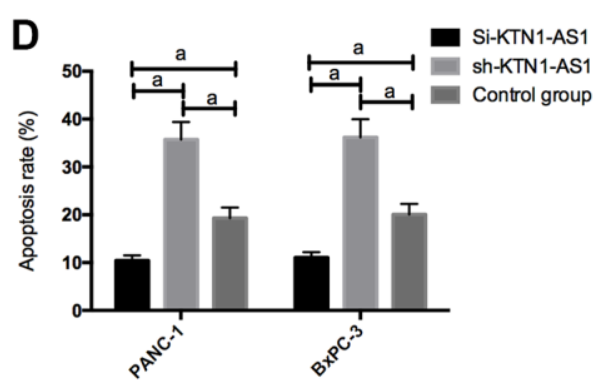
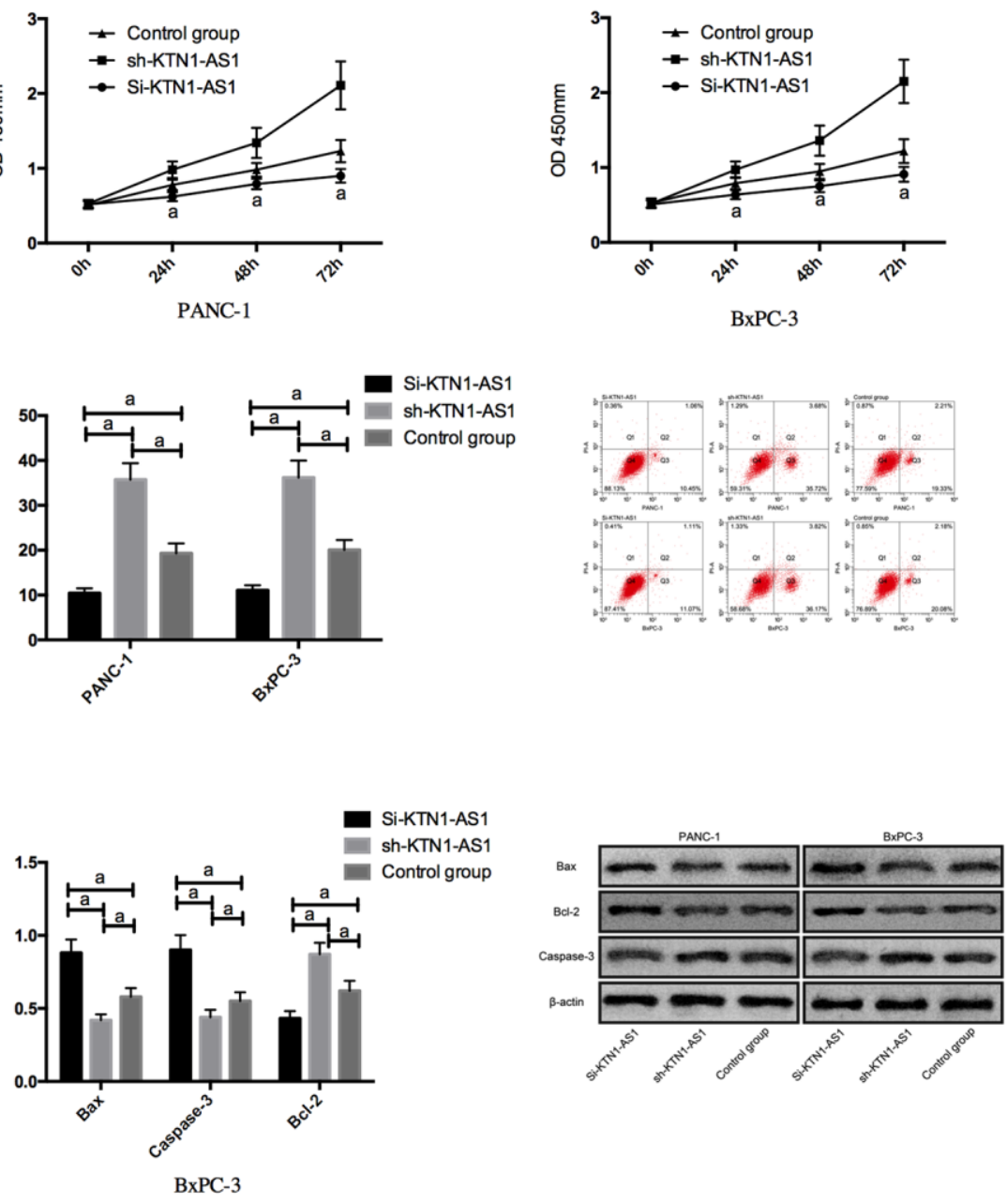

Figure 2. Effects of KTN1-AS1 on PC cells. (A) Expression of KTN1-AS1 in PC cells after transfection. (B) Effects of KTN1-AS1 on the proliferation of PC cells. (C) Effects of KTN1-AS1 on the invasion of PC cells. (D) Effects of KTN1-AS1 on the apoptosis rate of PC cells. (E) Effects of KTN1-AS1 on the apoptosis-related proteins of PC cells. a indicates $P<0.05$. 
Table 1. Relationship between KTN1-AS1 and pathological data of PC patients.

\begin{tabular}{|c|c|c|c|c|c|}
\hline \multirow{2}{*}{ Factors } & & \multicolumn{2}{|c|}{ IncRNA KTN1-AS1 } & \multirow{2}{*}{$X^{2}$ value } & \multirow{2}{*}{$P$ value } \\
\hline & & High expression $(n=56)$ & Low expression $(n=44)$ & & \\
\hline \multirow[t]{3}{*}{ Age } & & & & & 0.675 \\
\hline & $\begin{array}{c}\geq 59 \text { years old } \\
(n=53)\end{array}$ & $30(53.57)$ & $23(52.27)$ & 0.159 & \\
\hline & $\begin{array}{c}<59 \text { years old } \\
(n=47)\end{array}$ & $26(46.43)$ & $21(47.73)$ & & \\
\hline \multirow[t]{3}{*}{ Gender } & & & & & 0.957 \\
\hline & Male $(n=60)$ & $35(62.50)$ & $25(56.82)$ & 0.004 & \\
\hline & Female $(n=40)$ & $21(37.50)$ & $19(43.18)$ & & \\
\hline \multirow[t]{3}{*}{ Tumor size } & & & & & 0.776 \\
\hline & $\geq 3 \mathrm{~cm}(n=37)$ & $20(35.71)$ & $17(38.64)$ & 0.087 & \\
\hline & $<3 \mathrm{~cm}(n=63)$ & $36(64.29)$ & $27(61.36)$ & & \\
\hline \multirow[t]{3}{*}{ TNM staging } & & & & & $<0.001$ \\
\hline & Stage I-II & $40(71.43)$ & $13(29.55)$ & 20.66 & \\
\hline & Stage III & $16(28.57)$ & $31(70.45)$ & & \\
\hline \multirow[t]{3}{*}{$\begin{array}{c}\text { Differentiation } \\
\text { degree }\end{array}$} & & & & & $<0.001$ \\
\hline & Low differentiation & $32(57.14)$ & $39(88.64)$ & 10.57 & \\
\hline & $\begin{array}{c}\text { High }+ \text { moderate } \\
\text { differentiation }\end{array}$ & $24(42.86)$ & $5(11.36)$ & & \\
\hline \multirow[t]{3}{*}{ LNM } & & & & & $<0.001$ \\
\hline & With $(n=41)$ & $15(26.79)$ & $26(59.09)$ & 10.38 & \\
\hline & Without $(n=59)$ & $41(73.21)$ & $18(40.91)$ & & \\
\hline
\end{tabular}

The DLR assay revealed that KTN1-AS1-WT fluorescence activity was markedly inhibited by miR23b-3p-mimics. RIP experiments showed that the KTN1-AS1 and miR-23b-3p levels interacted with Ago2 were greatly higher than those of IgG. In addition, miR-23b-3p was underexpressed in PC tissues. Correlation analysis indicated a negative relationship of KTN1-AS1 and miR-23b-3p in PC tissues. We then transfected miR-23b-3p-mimics, sh-KTN1-AS1+miR23b-3p-mimics, and miR-NC, or sh-KTN1-AS1+miR$23 \mathrm{~b}-3 \mathrm{p}$-mimics, and miR-NC to cells. It turned out that after transfecting miR-23b-3p-mimics, the proliferation/invasion/migration of cells was observably inhibited and apoptosis was increased, while the biological function of cells after co-transfection with Sh-KTN1-AS and miR-23b-3p-mimics shown an opposite result. KTN1-AS1 inhibited miR-23b-3p expression by binding to miR-23b-3p, thereby promoting tumor growth. (Figure 3 and Supplementary Figure 1).

\section{KTN1-AS1 upregulated HMGB2 through competitive binding with miR-23b-3p}

To explore the potential downstream genes of KTN1AS1 in PC cells, we performed the RNA-seq analysis in PANC-1 cells transfected with sicontrol or siKTN1AS1. Among the differently expressed genes, we identified that HMGB2 presented a most significant downregulation by the depletion of KTN1-AS1 in PANC-1 cells (Supplementary Figure 3 ). We then selected HMGB2 for the further analysis. Moreover, we found the targeted binding sites between miR-23b-3p and HMGB2 using Targetscan7.2 online software. The DLR assay exhibited that the luciferase activity of HMGB2 was reduced by miR-23b-3p-mimics. What's more, HMGB2 was observed to be highly expressed in PC tissues. Correlation analysis revealed a positive relationship of HMGB2 and KTN1-AS1, and a negative relation between HMGB2 and miR-23b-3p. We then transfected miR-NC, miR-23b-3p-mimcis, sh-KTN1AS1+miR-23b-3p-mimics into cells to detect the expression of HMGB2. It was found that HMGB2 protein and mRNAs expression in the cells were inhibited after upregulation of miR-23b-3p, while the effects were reversed after the co-transfection of shKTN1-AS1 and miR-23b-3p-mimics. (Figure 4) The expression levels of HMGB2were verified by IHC in the clinical PC tissues and paracancer tissues. (Supplementary Figure 2).

\section{Down-regulation of HMGB2 expression inhibited growth and metastasis of $P C$ cells}

For the purpose of further exploring the impact of HMGB2, we silenced HMGB2, and found that 
proliferation/invasion was suppressed and apoptosis was elevated by Si-HMGB2, and the Bcl-2, N-cadherin, and vimentin expression was declined, and the bax and Caspase-3 expression was boosted. (Figure 5 and Supplementary Figure 1).

\section{KTN1-AS1-mediated miR-23b-3p/HMGB2 promoted tumor formation in nude mice}

For the sake of observing whether KTN1-AS1 affected solid tumor through miR-23b-3p/HMGB2 axis, we carried out tumorigenesis experiment in nude mice. By injecting miR-NC, miR-23b-3p-mimcis, sh-KTN1AS1+miR-23b-3p-mimics subcutaneously into nude mice, we found that the tumor size of nude mice injected with miR-23b-3p-mimcis decreased observably, while those of nude mice injected with sh-KTN1AS1+miR-23b-3p-mimics did not differ notably from those of miR-NC. Further measurement of the
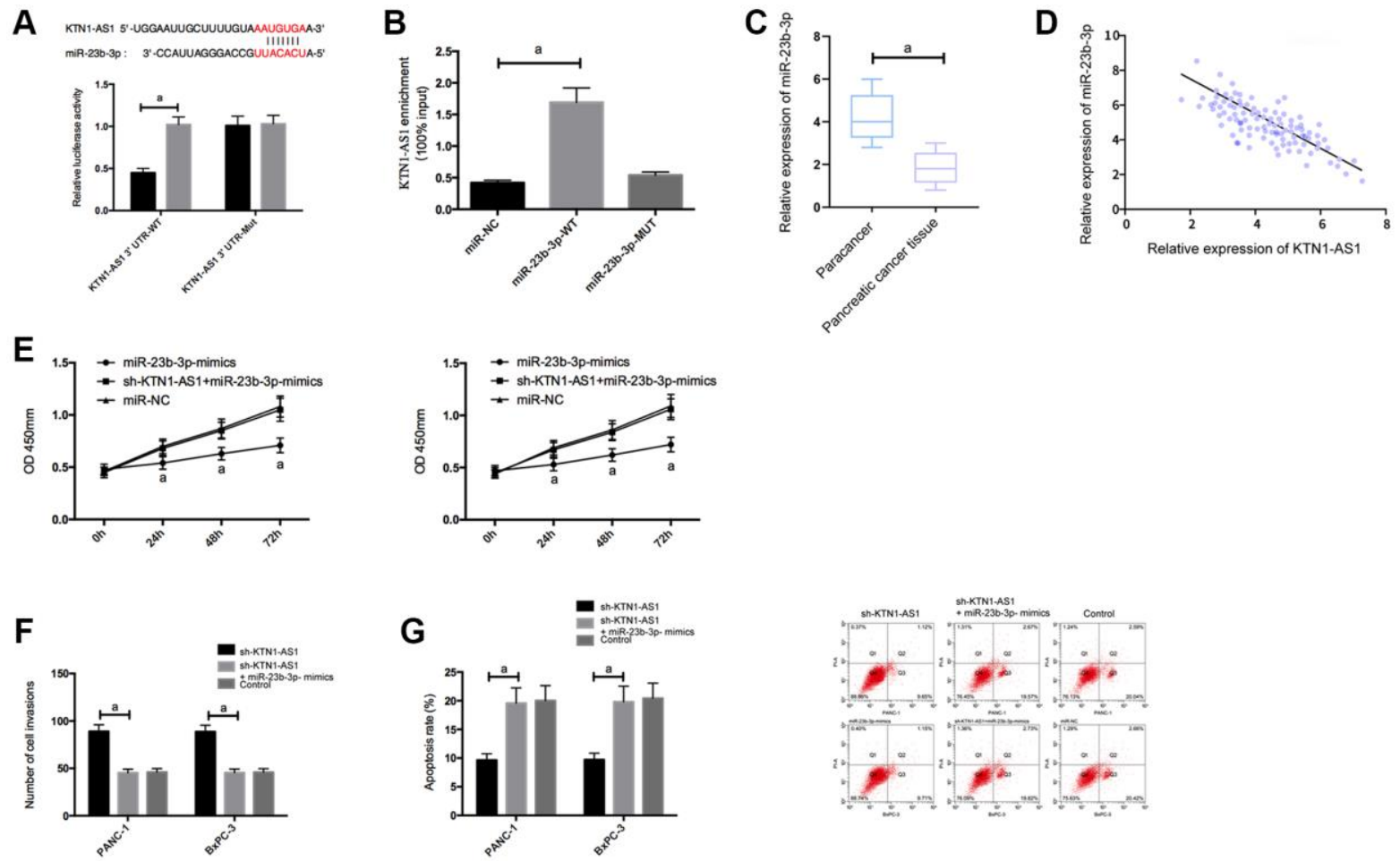

As a highly malignant and highly destructive tumor disease, pancreatic cancer (PC) has a very poor prognosis even after treatment [12]. In recent years, emerging evidence has shown that LncRNA plays a

tumor tissue of nude mice displayed that the expression levels of HMGB2 protein and mRNAs in the tumor of nude mice injected with miR-23b-3p-mimcis was significantly inhibited, while the expression levels of HMGB2 protein and mRNAs in the tumor of nude mice co-transfected with sh-KTN1-AS1+miR-23b-3p-mimics was reversed. (Figure 6) Meanwhile, we validated that KTN1-AS1 overexpression enhanced the tumor growth and the depletion of KTN1-AS1 or HMGB2 repressed the tumor growth in the nude mice. (Supplementary Figure 4).

\section{DISCUSSION}

\section{c}
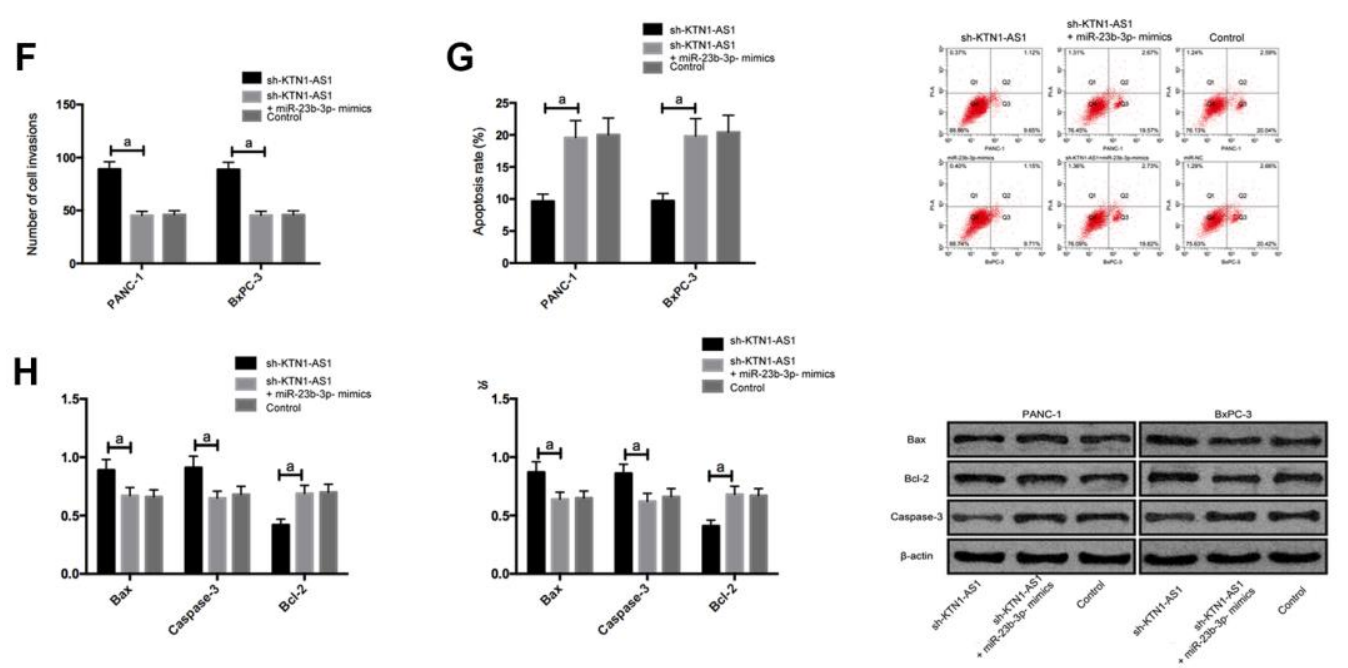

Figure 3. KTN1-AS1 inhibited its expression by binding to miR-23b-3p. (A) DLR assay. (B) RIP experiment. (C) MiR-23b-3p expression in PC tissue. (D) Correlation analysis between KTN1-AS1 and miR-23b-3p. (E) Effects of miR-23b-3p on the proliferation of PC cells. (F) Effects of miR-23b-3p on the invasion of PC cells. (G) Effects of miR-23b-3p on the apoptosis rate of PC cells. (H) Effects of miR-23b$3 p$ on apoptosis-related proteins in PC cells. a indicates $P<0.05$. 
A Position 64-71 of HMGB2 3' UTR 5' ....AAUUAUUUUGCUAAGAAUGUGAA... hsa-miA-23b-3p $\quad$ 3. CCAUUAGGaCCGUUACACUA

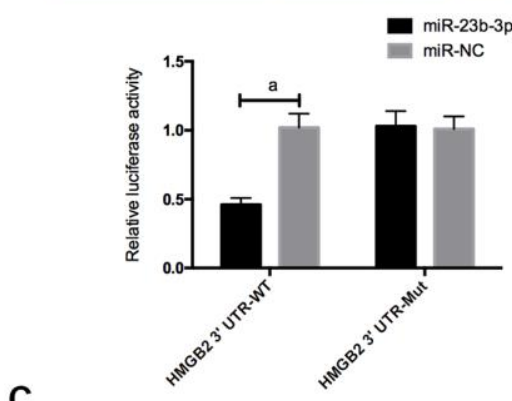

C

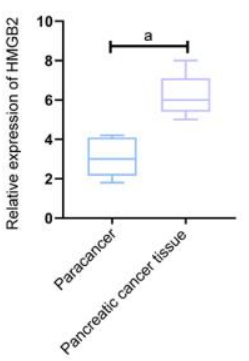

B

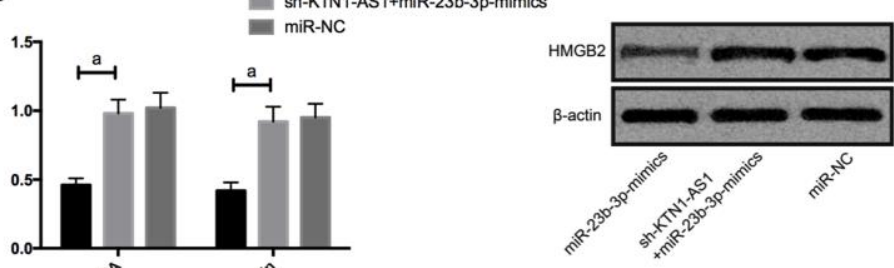

D

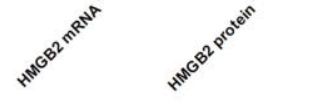

E

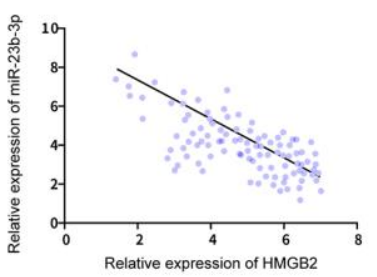

Figure 4. KTN1-AS1 competitively bound to miR-23b-3p to up-regulate the expression of HMGB2. (A) DLR assay. (B) Effects of KTN1-AS1 and miR-23b-3p on HMGB2 protein expression. (C) HMGB2 expression in PC tissue. (D) Correlation analysis between HMGB2 and KTN1-AS1. (E) Correlation analysis between HMGB2 and miR-23b-3p. a indicates $P<0.05$.

A

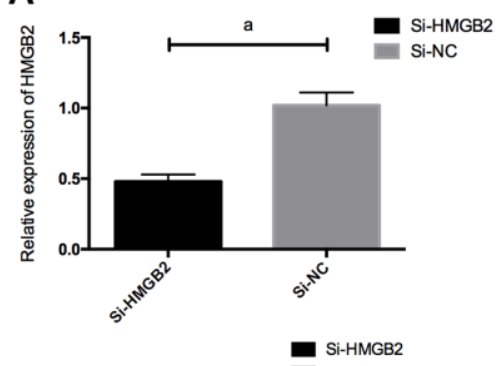

C

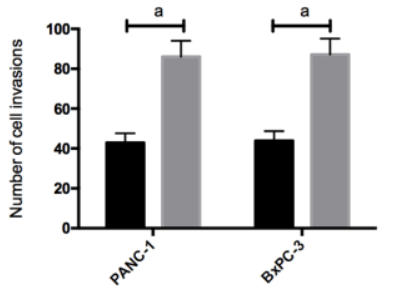

E

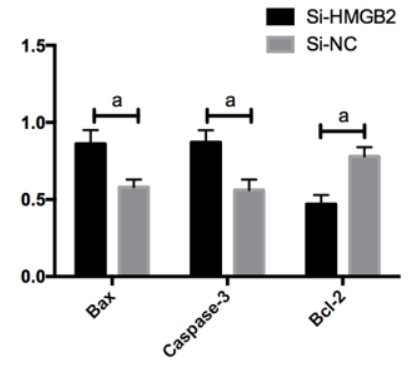

B
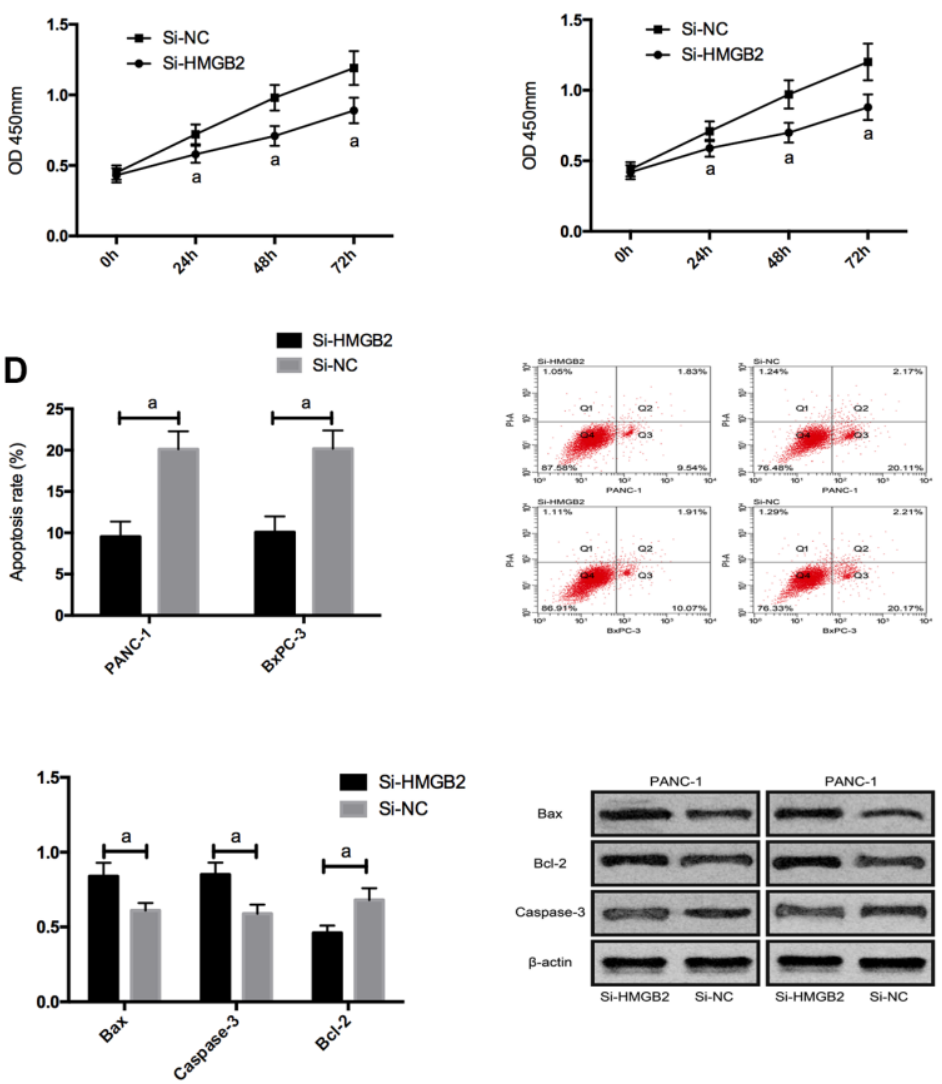

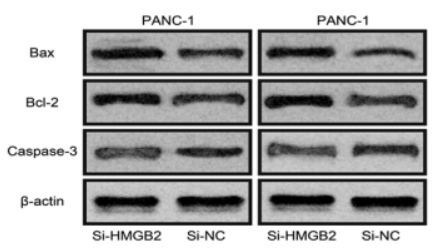

Figure 5. Effects of HMGB2 on PC cells. (A) HMGB2 expression in PC cells after transfection. (B) Effects of HMGB2 on proliferation of PC cells. (C) Effects of HMGB2 on invasion of PC cells. (D) Effects of HMGB2 on apoptosis rate of PC cells. (E) Effects of HMGB2 on apoptosisrelated proteins in $P C$ cells. a indicates $P<0.05$. 
extremely important part in the progression of cancer. For example, LncRNA HOTAIR [13] and other lncRNAs have been reported as biomarkers or potential therapeutic targets in a variety of tumors. Another case is that LncRNA MALAT1 [14] has shown to be a key regulator of the metastatic phenotype of lung cancer cells. Apart from that, the role of LncRNA in PC has been discussed extensively in the past. For example, some [15] have revealed that LINC01133 and LINC00205 can be used as prognostic biomarkers of PC. Another research [16] has reported that, by interacting with miR-133, LncRNA MIAT affects the proliferation and metastasis of PC. These reports indicate that LncRNAs widely contribute to the modulation of PC development.

As one of the most recently discovered LncRNAs in recent years, LncRNA KTN1-AS1 has been found to accelerate the progression of colorectal cancer cells [9]. Its role in PC, however, remains poorly understood.

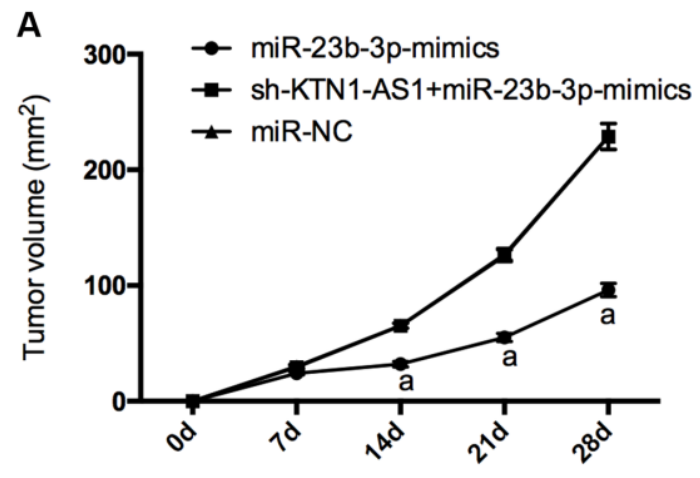

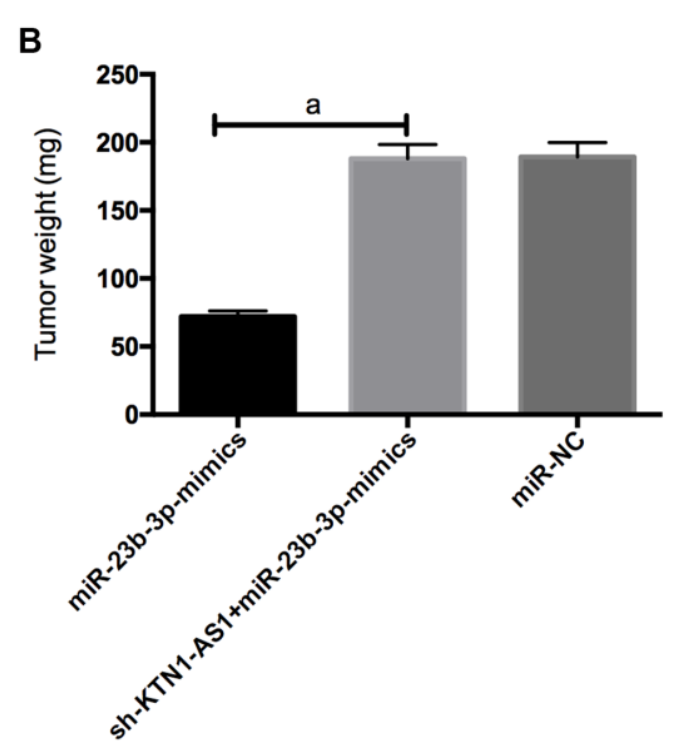

Here, KTN1-AS1 was highly expressed in PC tissues and cells, and clinical analysis also showed that KTN1AS1 was bound up with the clinicopathological stage, differentiation degree, and LNM of patients with PC. In addition, the ROC curve analysis revealed a higher value of KTN1-AS1 in the diagnosis of PC, plus that survival incidence of patients with high KTN1-AS1 expression was also noticeably reduced, indicating that the occurrence and development of PC were closely related to the expression of KTN1-AS1. Moreover, We found for the first time that increasing the expression of KTN1-AS1 could noticeably promote the invasion and proliferation of PC cells and inhibit apoptosis, while on the contrary, inhibited KTN1-AS1 presented a conversed effect, which suggested that KTN1-AS1 played a role in promoting oncogenes in PC. These findings indicate that KTN1-AS1 contributes to the malignant progression and is closely associated with clinical development of KTN1-AS1, provide novel evidence of the important function of LncRNA in the
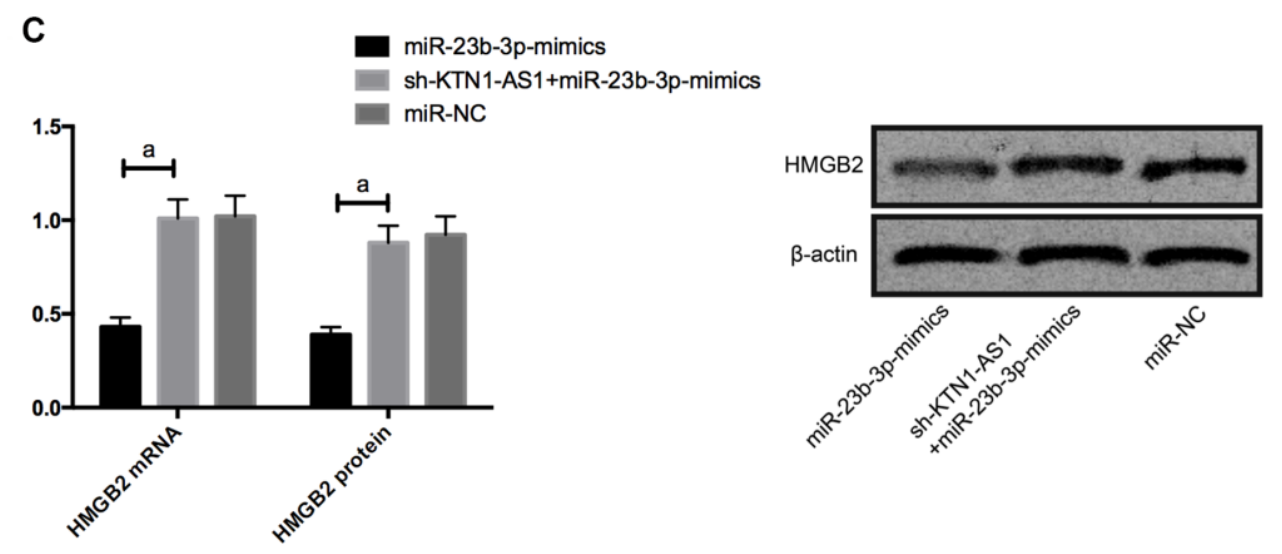

Figure 6. KTN1-AS1-mediated miR-23b-3p/HMGB2 promoted tumor formation in nude mice. (A) Changes of subcutaneous tumor volume in nude mice within 28 days. (B) Tumor volume of nude mice was on the 28th day. (C) Relative expression of HMGB2 protein and mRNAs in nude mouse tumor. a indicates $P<0.05$. 
regulation of PC progression. There are still some shortcomings in the current investigation. Although the association of KTN1-AS1 with the clinical characteristics of PC was shown, the diagnostic and prognostic value and clinical significance of KTN1-AS1 should be explored in future investigations by more clinical studies. Meanwhile, we just investigated the effect of KTN1-AS1 on PC in PANC-1 and BxPC-3 cell lines, we will validate our conclusion in other $\mathrm{PC}$ cell liens in future investigation. In the past, studies [10] found that KTN1AS1 also served as an oncogene in hepatocellular carcinoma, which was consistent with the effects of KTN1-AS1 in our research. The specific mechanism of KTN1-AS1 in PC, however, remains elusive.

It is well known that LncRNA can regulate the level of post-transcriptional miRNA by exerting its ceRNA function [17]. In present study, the binding targets of miR-23b-3p and KTN1-AS1 were found through bioinformatics prediction, which was then verified by DLR and RIP experiments. According to past reports, miR-23b-3p was underexpressed in gastric cancer [18] and tongue cancer [19], and likewise, here we discovered the low expression of miR-23b-3p in PC, and through correlation analysis, we identified a negative correlation between KTN1-AS1 and miR-23b$3 \mathrm{p}$. Then we found that the proliferation/invasion of PC cells was notably inhibited and the apoptosis was raised after miR-23b-3p overexpression. Previous literature [20] has supported that miR-23b-3p can hinder the occurrence and progression of $\mathrm{PC}$ by directly regulating the ANXA2, which is in line with our findings on miR$23 b-3 p$, but the downstream mechanism of our study is not repeated with this study. In the hope of further studying the effects of KTN1-AS1 and miR-23b-3p on PC cells, we cotransfected sh-KTN1-AS1 and miR-23b3p-mimics into PC cells. It was observed that sh-KTN1AS1 reversed the inhibitory effect of miR-23b-3pmimics on the growth of PC cells and the promotion of apoptosis, which was indicative that up-regulating the expression of KTN1-AS1 can promote the growth of PC by regulating miR-23b-3p. These data indicate that miR-23b-3p is involved in KTN1-AS1-mediated PC progression, presenting the innovative evidence of the tumor suppressive function of miR-23b-3p. Meanwhile, we elucidate the correlation of KTN1-AS1 with miR$23 b-3 p$ in the modulation of PC progression. The clinical significance of miR-23b-3p needs to be explored by more investigations.

miRNA is known to affect cell function by regulating its targeted mRNA [21]. High-mobility group B proteins can fine-tune the internal environment of the body by interacting with nucleosomes, transcription factors and histones [22, 23]. Many studies [24, 25] have exhibited that the up-regulation of HMGB is related to the enhanced proliferation, invasion ability and decline of apoptosis of many malignant tumor cells. Other studies [26] have clearly pointed out that HMGB2 can be used as a prognostic indicator for patients with PC. In current study, we predicted the targeting association of HMGB2 with miR-23b-3p, and then verified this targeting relationship by DLR, indicating that KTN1-AS1 might be a molecular sponge for miR-23b-3p to regulate HMGB2 expression. So, then we confirmed our hypothesis through experiments, sh-KTN1-AS1 could reverse the inhibitory effect of miR-23b-3p-mimics on HMGB2 expression. Furthermore, the tumor formation experiment in nude mice further confirmed that KTN1AS1 promoted the growth of PC by targeting miR-23b$3 \mathrm{p} / \mathrm{HMGB} 2$ axis. Our finding provides new insight into the mechanism by which KTN1-AS1 contributes to PC progression by regulating miR-23b-3p/HMGB2 axis. The miR-23b-3p/HMGB2 axis may just one of the downstream mechanisms underlying KTN1-AS1mediated PC development and other potential molecules should be explored in the future. And more signaling pathways in which KTN1-AS1 may function will be confirmed by more investigations.

However, there are still some shortcomings in this study. A case is that the downstream signaling pathway of HMGB2 remains elusive. In the follow-up research, we will carry out further basic experiments to provide more data to support our conclusions.

\section{MATERIALS AND METHODS}

\section{Clinical specimens}

After patients' consents, paired PC tissues and paracancerous tissues were taken from 100 PC patients diagnosed and treated in the First Affiliated Hospital of China Medical University, and the specimens were then frozen in liquid nitrogen tanks for follow-up experiments. Inclusion criteria: Patients pathologically diagnosed as PC. Exclusion criteria: Patients who had received any chemoradiotherapy prior to this study; Patients with other malignancies; Patients with severe hepatorenal dysfunction; Patients with severe infection or immune system disorders. Having been approved by the Medical Ethics Committee of the First Affiliated Hospital of China Medical University, this study was carried out after the consent of all enrolled patients or their families, with written informed consent obtained. The expression levels of HMGB2, Bax, Bcl-2, and caspese-3 were verified by immunohistochemistry (IHC) in the samples.

\section{Cell culture, passage and transfection}

PC cell lines (PANC-1, SW1990, BxPC-3, AsPC-1) and human normal pancreatic duct epithelial cells 
HPDE were all purchased from the ATCC. The PC cell line was cultured at $37^{\circ} \mathrm{C}$ with $5 \% \quad \mathrm{CO}_{2}$ in a medium containing 10\% PBS (HyClone, Logan, UT, USA) DMEM (Invitrogen, USA). When digestion finished, the cells were cultured and for passage before transfecting. Since RT-PCR results showed that KTN1-AS1 had the most obvious changes in PANC-1 and BxPC-3, these two were selected for the research objects. MiR-23b-3p-mimics, miR negative control (miR-NC), pcDBA3.1 vector containing targeted inhibition KTN1-AS1 plasmid (si-KTN1AS1), pcDNA3.1 vector containing KTN1-AS1 plasmid (sh-KTN1-AS1), pcDNA3.1 vector containing targeted inhibition HMGB2 plasmid (siPBX3), and control sequence (Control) were transfected into cells with Lipofectamine ${ }^{\mathrm{TM}} 2000$ kit, respectively. Strictly abode by the instructions, the operation was carried out. The sequences used were as follows: miR-23b-3p mimics, 5'ATCACATTGCCAGGGATTACC-3; si-KTN1-AS1, 5'-CTTTCATTTCTGCTATCCC-3'; si-PBX3, 5'CCGUCAAUUUCGCGGAAUUTT-3'.

\section{RNA-Seq analysis}

The RNA-seq analysis was performed to explore the potential correlation of IncRNAs with pancreatic cancer. Total RNA was extracted from 3 paired pancreatic cancer tissues and paracancer tissues. Meanwhile, the RNA-seq analysis was performed to explore the potential downstream miRNAs and mRNAs of KTN1-AS1. Total RNA was extracted from PANC-1 cells transfected with sicontrol or siKTN1-AS1. The RNA sequencing assay was performed to at KangChen Bio-Tech (Shanghai, China) using Illumina HiSeq 4000 (Illumina, San Diego, CA, USA). The differential expression was analyzed based on $P$ value and fold change (fold change $\geq 2$ and $P$ value $<0.05$ ).

\section{qRT-PCR detection}

RNA was isolated from cells and tissues by using a TRIzol reagent (Invitrogen, USA) in accordance with the protocol, followed by reverse-transcription to cDNA by using PrimeScript Master Mix (Takara, Japan). The levels of RNAs were quantified by using a SYBR Premix Ex Taq Kit (Takara). GAPDH and U6 were used as internal control for normalization of gene expression using the $2^{-\Delta \Delta \mathrm{Ct}}$ method. The primer sequences are detailed in Table 2.

\section{Detection of protein expression by western blot}

The samples were homogenized by RIPA lysis buffer that contains proteinase inhibitors (Sigma) to extract total proteins. The proteins were quantified by BCA assay kit (Beyotime, China). An equal amount of proteins $(30 \mu \mathrm{g})$ were divided on SDS-PAGE gel, shifted to NC membranes, blocked by 5\% silk milk and hatched with specific primary antibodies against HMGB2 (1: 500), Bax (1: 500), Bcl-2 (1: 500), Caspese-3 (1: 500), and $\beta$-Actin (1: 1000) at $4{ }^{\circ} \mathrm{C}$ overnight. Next day, the protein bands were incubated with specific HRP-conjugated anti-mouse and antirabbit secondary antibodies at room temperature for 45 minutes, visualized by using an ECL solution (Millipore, Germany) in a Gel Image system (Bio-Rad, Hercules, CA, USA). HMGB2, Bax, Bcl-2, Caspese-3 and $\beta$-Actin antibody were all acquired from Santa Cruz Biotechnology (Santa Cruz, CA, USA).

\section{Cell proliferation assessed by CCK-8}

Cell proliferation was detected according to the instructions of CCK-8 kit (Promega, Madison, WI, USA). Forty-eight hours after transfection, cells were gathered and diluted into $3 \times 10^{4} \mathrm{cell} / \mathrm{mL}$, and inoculated in 96-well plates, $10 \mu \mathrm{L} \mathrm{CCK8}$ solution was added to each well and continued to culture in an incubator with $5 \% \mathrm{CO}_{2}$ at $37^{\circ} \mathrm{C}$ for $2 \mathrm{~h}$. With the help of a microplate reader, the OD value at $450 \mathrm{~nm}$ was finally tested to detect cell proliferation. The experiment was duplicated three times.

\section{Transwell detection}

According to the kit instructions (Reanta Biotechnology Co., Ltd., Beijng, China), cells were collected 24 hours after transfection and inoculated on 24-well plates $(3 \times$ $10^{4}$ cells/well). For cell invasion, cells were suspended in FBS-free medium, and seeded in the upper chambers of Transwell plates (Corning, NY, USA), while the lower chambers were filled with complete medium. The upper chambers were collected after incubation for 48 hours, washed in PBS, fixed in methanol, and dyed with $1 \%$ crystal violet. Finally, the cell invasion was observed by a microscope.

\section{Apoptosis test}

On the basis of the instructions of Annexin V-FITC/PI apoptosis kit (Biolab Biotechnology Co., Ltd., Beijing, China), the transfected cells were digested with $0.25 \%$ trypsin before rinsing with PBS twice. Then, the cells (1 $\times 10^{6}$ ) were treated with binding buffer, and then AnnexinV-FITC and PI were added successively to incubate for $5 \mathrm{~min}$ away from light at room temperature. Finally, apoptosis was detected by FACSVerse flow cytometry (Becton Dickinson Company, NJ, USA), and the average value was obtained by repeating the experiment for 3 times. 
Table 2. Primer sequences.

\begin{tabular}{lll}
\hline Factors & Upstream primer & Downstream primer \\
\hline miR-23b-3p & 5'-GAGCATCACATTGCCAGGG-3' & 5'-GTGCAGGGTCCGAGGT-3' \\
U6 & 5'-GCTTCGGCAGCACATATACTAAAAT-3' & 5'-CGCTTCACGAATTTGCGTGTCAT-3' \\
KTN1-AS1 & 5'-ATGCACACTTCTCGGCTAAGAGTC-3' & 5'-CTACAATGCCACAAGTGATTCCAGC-3' \\
HMGB2 & 5'-GGACCCCAATGCTCCTAAAAGGCC-3' & 5'-TGCCCTTGGCACGATATGCAGCA-3' \\
\hline
\end{tabular}

Targeting correlation of miR-23b-3p between KTN1-AS1 and HMGB2 determined by DLR gene assay

The wild type (WT) and mutated (MUT) sequences of KTN1-AS1 and the 3'-UTR of HMGB2 were inserted into PmirGLO plasmids. Cells were transfected with the constructed vectors and miR-23b-3p mimics, along with the pRL-TK as internal control. The luciferase activity was determined after 48-hours incubation with a dual luciferase reporter assay system (Promega).

\section{RNA binding protein immunoprecipitation (RIP experiment)}

Magna RIP RNA-binding protein immunoprecipitation kit (Millipore) was used for RIP assay in accordance with manufacturer's instruction. In short, cells lysates were obtained by using lysis buffer and sonication, then incubated with Ago2 antibody or IgG antibodyconjugated beads for 3 hours at room temperature. The precipitation was washed and eluted, the enriched KTN1-AS1 and miR-23b-3p were analyzed by qRTPCR assay.

\section{Tumorigenesis experiment in nude mice}

Animal experiments were conducted under the approval of the Animal Research Ethics Committee of the First Affiliated Hospital of China Medical University. 4-6 weeks old male nude mice (Charles River, China) were selected, with 5 in each group. After transfection, 200 $\mathrm{mL}$ of PANC-1 cells $\left(3 \times 10^{6}\right)$ were injected subcutaneously into the left side of the back of each nude mouse. Tumor size was measured regularly and calculated using formula $0.52 \times$ tumor length $\times$ tumor short diameter ${ }^{2}$. The animals were euthanized $30 \mathrm{~d}$ after injection to remove the tumor and measure its volume and weight.

\section{Statistical analysis}

Data were expressed as mean \pm SD and analyzed by using SPSS 20.0 software. Comparison between two or multiple groups were determined by student's $t$ test or one-way ANOVA analysis followed by LSD- $t$, respectively. $p<$ 0.05 was considered as statistically significant.

\section{AUTHOR CONTRIBUTIONS}

Zhang ZB designed and coordinated the study, performed the experiments and prepared the manuscript. Liu N provided assistance in the design of the study and participated in manuscript preparation. Zhang ZB and Liu N participated in data gathering. All authors have read and approved the final manuscript.

\section{CONFLICTS OF INTEREST}

The authors declare no conflicts of interest related to this study.

\section{FUNDING}

This study was supported by the First Affiliated Hospital of China Medical University.

\section{Editorial note}

${ }^{\&}$ This corresponding author has a verified history of publications using a personal email address for correspondence.

\section{REFERENCES}

1. Siegel RL, Miller KD, Jemal A. Cancer Statistics, 2017. CA Cancer J Clin. 2017; 67:7-30. https://doi.org/10.3322/caac.21387 PMID:28055103

2. Zhu H, Li T, Du Y, Li M. Pancreatic cancer: challenges and opportunities. BMC Med. 2018; 16:214. https://doi.org/10.1186/s12916-018-1215-3 PMID:30463539

3. Rombouts SJ, Vogel JA, van Santvoort HC, van Lienden KP, van Hillegersberg R, Busch OR, Besselink MG, Molenaar IQ. Systematic review of innovative ablative therapies for the treatment of locally advanced pancreatic cancer. $\mathrm{Br} J$ Surg. 2015; 102:182-93. https://doi.org/10.1002/bjs. 9716 PMID:25524417

4. Hwang JA, Jang KM, Kim SH, Kang TW, Song KD, Cha 
DI, Ahn S. Integration of different criteria for borderline resectable pancreatic cancer using classification tree analysis: the use of radiological tumour-vascular interface in correlation with surgical and pathological outcomes. Clin Radiol. 2018; 73:321.e1-e10.

https://doi.org/10.1016/j.crad.2017.11.001

PMID:29221719

5. Batista PJ, Chang HY. Long noncoding RNAs: cellular address codes in development and disease. Cell. 2013; 152:1298-307.

https://doi.org/10.1016/j.cell.2013.02.012

PMID:23498938

6. Dong $\mathrm{P}$, Xiong $\mathrm{Y}$, Yue J, Hanley SJB, Kobayashi N, Todo Y, Watari H. Long Non-coding RNA NEAT1: A Novel Target for Diagnosis and Therapy in Human Tumors. Front Genet. 2018; 9:471.

https://doi.org/10.3389/fgene.2018.00471 PMID:30374364

7. Liu $X H$, Sun $M$, Nie $F Q$, Ge $Y B$, Zhang EB, Yin DD, Kong $\mathrm{R}$, Xia R, Lu KH, Li JH, De W, Wang KM, Wang ZX. Lnc RNA HOTAIR functions as a competing endogenous RNA to regulate HER2 expression by sponging miR331-3p in gastric cancer. Mol Cancer. 2014; 13:92. https://doi.org/10.1186/1476-4598-13-92 PMID:24775712

8. Gao H, Gong N, Ma Z, Miao X, Chen J, Cao Y, Zhang G. LncRNA ZEB2-AS1 promotes pancreatic cancer cell growth and invasion through regulating the miR204/HMGB1 axis. Int J Biol Macromol. 2018; 116:545-51. https://doi.org/10.1016/i.ijbiomac.2018.05.044 PMID:29753015

9. Cao W, Liu JN, Liu Z, Wang X, Han ZG, Ji T, Chen WT, Zou $X$. A three-IncRNA signature derived from the Atlas of ncRNA in cancer (TANRIC) database predicts the survival of patients with head and neck squamous cell carcinoma. Oral Oncol. 2017; 65:94-101.

https://doi.org/10.1016/i.oraloncology.2016.12.017 PMID:28109476

10. Zhang L, Wang L, Wang Y, Chen T, Liu R, Yang W, Liu $Q$, Tu K. LncRNA KTN1-AS1 promotes tumor growth of hepatocellular carcinoma by targeting miR23c/ERBB2IP axis. Biomed Pharmacother. 2019; 109:1140-47.

https://doi.org/10.1016/i.biopha.2018.10.105 PMID:30551364

11. Wu B, Xing C, Tao J. Upregulation of microRNA-23b$3 p$ induced by farnesoid $X$ receptor regulates the proliferation and apoptosis of osteosarcoma cells. J Orthop Surg Res. 2019; 14:398.

https://doi.org/10.1186/s13018-019-1404-6 PMID: $\underline{31779647}$
12. Spivak-Kroizman TR, Hostetter G, Posner R, Aziz M, $\mathrm{Hu} C$, Demeure MJ, Von Hoff $D$, Hingorani SR, Palculict TB, Izzo J, Kiriakova GM, Abdelmelek M, Bartholomeusz G, et al. Hypoxia triggers hedgehogmediated tumor-stromal interactions in pancreatic cancer. Cancer Res. 2013; 73:3235-47. https://doi.org/10.1158/0008-5472.CAN-11-1433 PMID:23633488

13. Tang $Q$, Hann SS. HOTAIR: An Oncogenic Long NonCoding RNA in Human Cancer. Cell Physiol Biochem. 2018; 47:893-913.

https://doi.org/10.1159/000490131

PMID:29843138

14. Gong N, Teng X, Li J, Liang XJ. Antisense Oligonucleotide-Conjugated Nanostructure-Targeting IncRNA MALAT1 Inhibits Cancer Metastasis. ACS Appl Mater Interfaces. 2019; 11:37-42.

https://doi.org/10.1021/acsami.8b18288 PMID:30548064

15. Giulietti M, Righetti A, Principato G, Piva F. LncRNA co-expression network analysis reveals novel biomarkers for pancreatic cancer. Carcinogenesis. 2018; 39:1016-25. https://doi.org/10.1093/carcin/bgy069 PMID:29796634

16. Li TF, Liu J, Fu SJ. The interaction of long non-coding RNA MIAT and miR-133 play a role in the proliferation and metastasis of pancreatic carcinoma. Biomed Pharmacother. 2018; 104:145-50. https://doi.org/10.1016/j.biopha.2018.05.043 PMID:29772434

17. De Martino $M$, Forzati $F$, Marfella $M$, Pellecchia $S$, Arra C, Terracciano L, Fusco A, Esposito F. HMGA1P7pseudogene regulates $\mathrm{H} 19$ and Igf2 expression by a competitive endogenous RNA mechanism. Sci Rep. 2016; 6:37622.

https://doi.org/10.1038/srep37622 PMID:27874091

18. Xian $X$, Tang L, Wu C, Huang L. miR-23b-3p and miR$130 a-5 p$ affect cell growth, migration and invasion by targeting CB1R via the $W n t / \beta$-catenin signaling pathway in gastric carcinoma. Onco Targets Ther. 2018; 11:7503-12. https://doi.org/10.2147/OTT.S181706 PMID: $\underline{30498363}$

19. Grossi I, Arici B, Portolani N, De Petro G, Salvi A. Clinical and biological significance of miR-23b and miR-193a in human hepatocellular carcinoma. Oncotarget. 2017; 8:6955-69. https://doi.org/10.18632/oncotarget.14332 PMID:28036298

20. Wei DM, Dang YW, Feng ZB, Liang L, Zhang L, Tang 
RX, Chen ZM, Yu Q, Wei YC, Luo DZ, Chen G. Biological Effect and Mechanism of the miR-23b-3p/ANXA2 Axis in Pancreatic Ductal Adenocarcinoma. Cell Physiol Biochem. 2018; 50:823-40.

https://doi.org/10.1159/000494468

PMID:30355917

21. Amirkhah R, Schmitz $U$, Linnebacher $M$, Wolkenhauer $O$, Farazmand A. MicroRNA-mRNA interactions in colorectal cancer and their role in tumor progression. Genes Chromosomes Cancer. 2015; 54:129-41. https://doi.org/10.1002/gcc.22231 PMID:25620079

22. Bianchi ME, Beltrame M. Upwardly mobile proteins. Workshop: the role of HMG proteins in chromatin structure, gene expression and neoplasia. EMBO Rep. 2000; 1:109-14.

https://doi.org/10.1093/embo-reports/kvd030 PMID:11265747

23. Bianchi ME, Agresti A. HMG proteins: dynamic players in gene regulation and differentiation. Curr Opin Genet Dev. 2005; 15:496-506.

https://doi.org/10.1016/j.gde.2005.08.007

PMID: 16102963

24. Liu PL, Tsai JR, Hwang JJ, Chou SH, Cheng YJ, Lin FY, Chen $Y L$, Hung $\mathrm{CY}$, Chen WC, Chen $\mathrm{YH}$, Chong IW. High-mobility group box 1-mediated matrix metalloproteinase- 9 expression in non-small cell lung cancer contributes to tumor cell invasiveness. Am J Respir Cell Mol Biol. 2010; 43:530-38.
https://doi.org/10.1165/rcmb.2009-02690C

PMID:19933377

25. Guo ZS, Liu Z, Bartlett DL, Tang D, Lotze MT. Life after death: targeting high mobility group box 1 in emergent cancer therapies. Am J Cancer Res. 2013; 3:1-20.

PMID:23359863

26. Cai X, Ding H, Liu Y, Pan G, Li Q, Yang Z, Liu W. Expression of HMGB2 indicates worse survival of patients and is required for the maintenance of Warburg effect in pancreatic cancer. Acta Biochim Biophys Sin (Shanghai). 2017; 49:119-27. https://doi.org/10.1093/abbs/gmw124 PMID:28069585 


\section{SUPPLEMENTARY MATERIALS}

\section{Supplementary Figures}

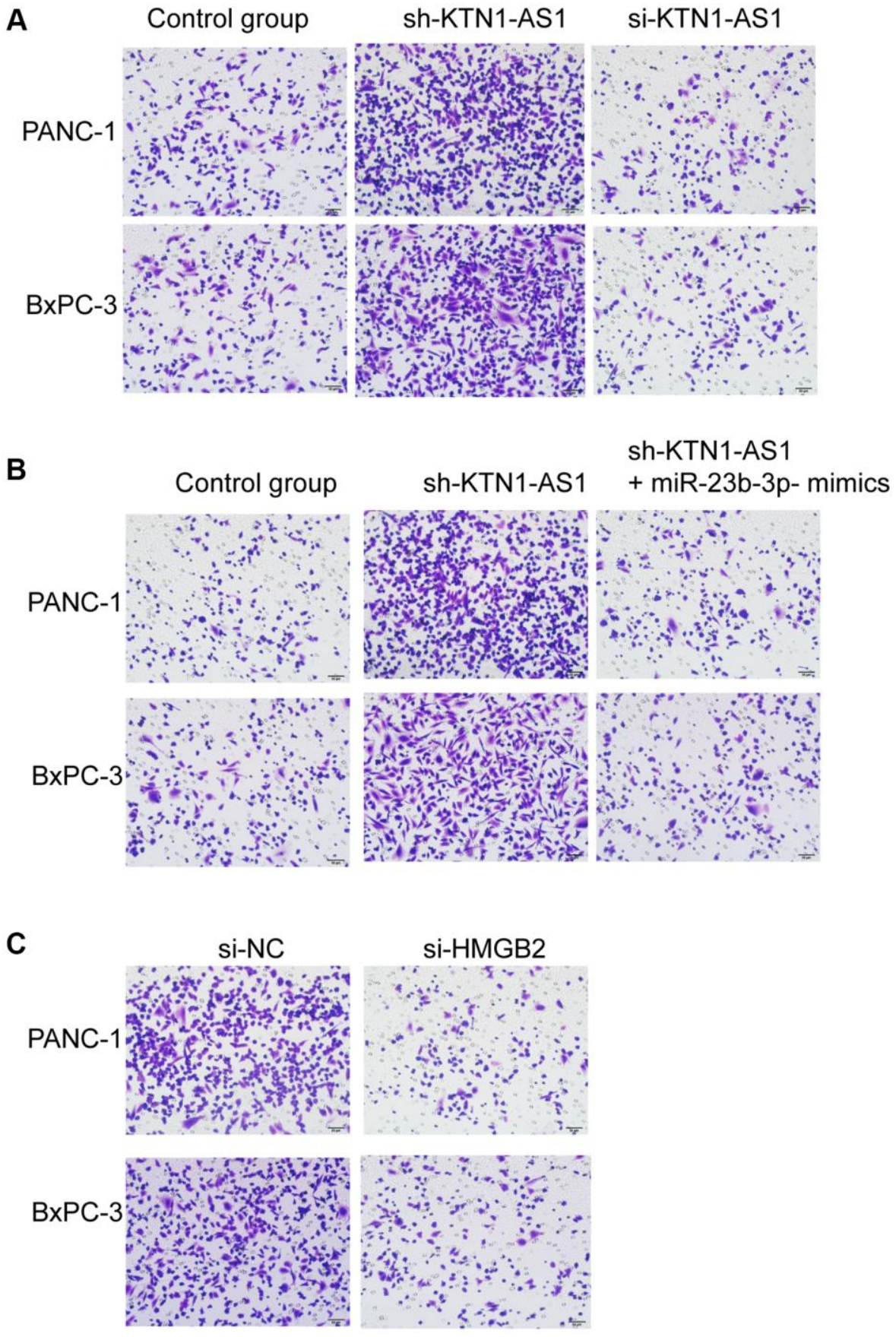

Supplementary Figure 1. The images of the invasion experiments. (A) Effects of KTN1-AS1 on the invasion of PC cells, related to Figure 2C. (B) Effects of miR-23b-3p on the invasion of PC cells, related to Figure 3F. (C) Effects of HMGB2 on the invasion of PC cells, related to Figure $5 \mathrm{C}$. 
A

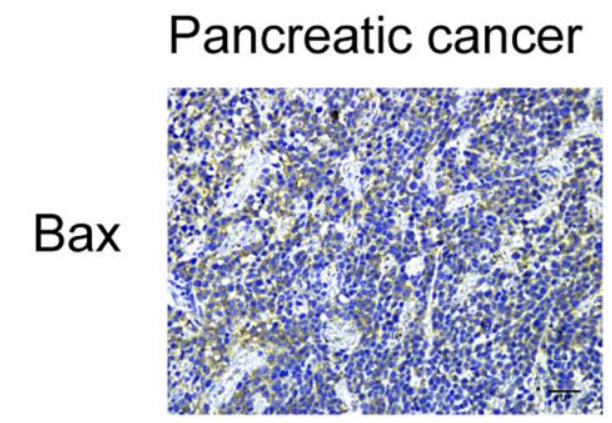

caspese-3

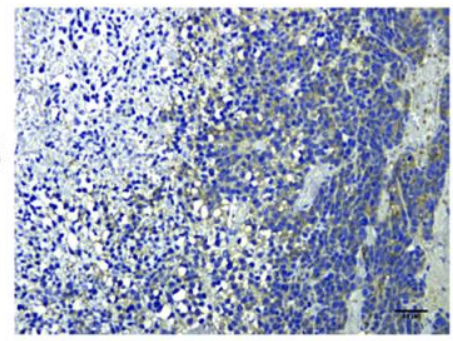

$\mathrm{Bcl}-2$

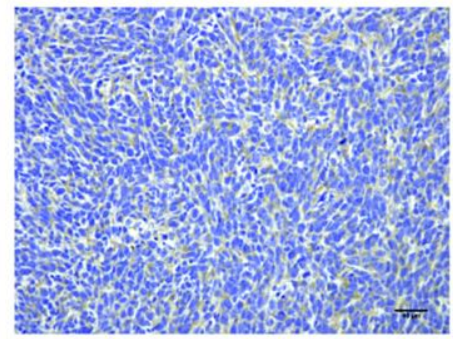

HMGB2

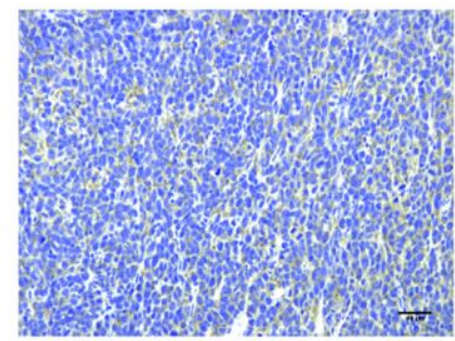

\section{Paracancer}
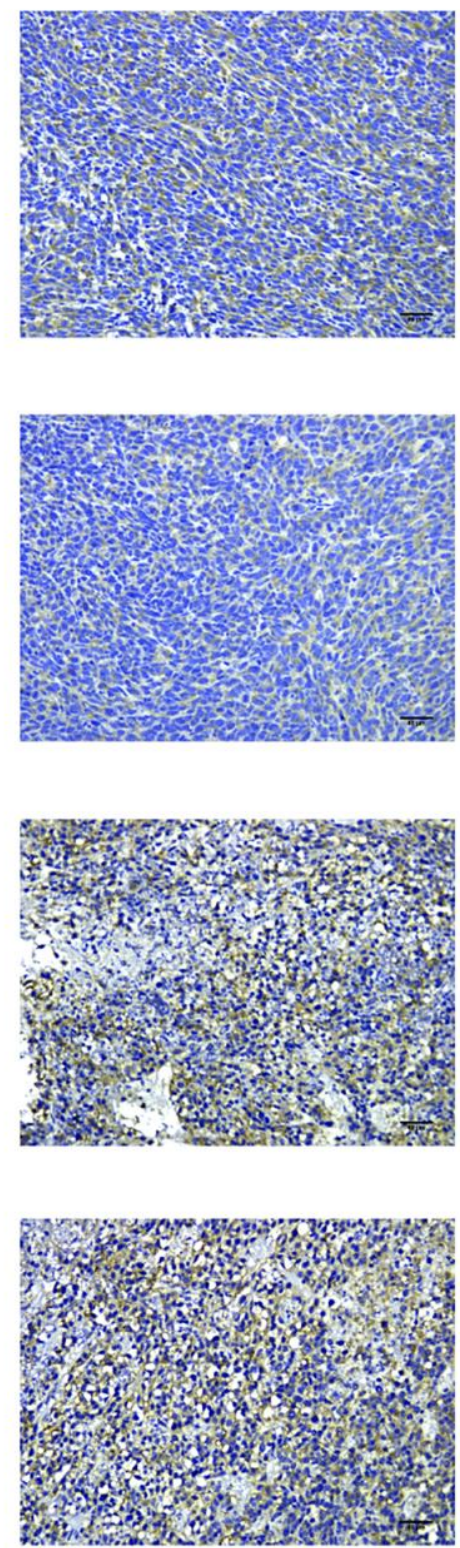

Supplementary Figure 2. The validation of expression levels of HMGB2, Bax, Bcl-2, and caspese-3 in clinical PC tissues. (A) The expression levels of HMGB2, Bax, BCl-2, and caspese-3 were verified by IHC in the clinical PC tissues and paracancer tissues. 

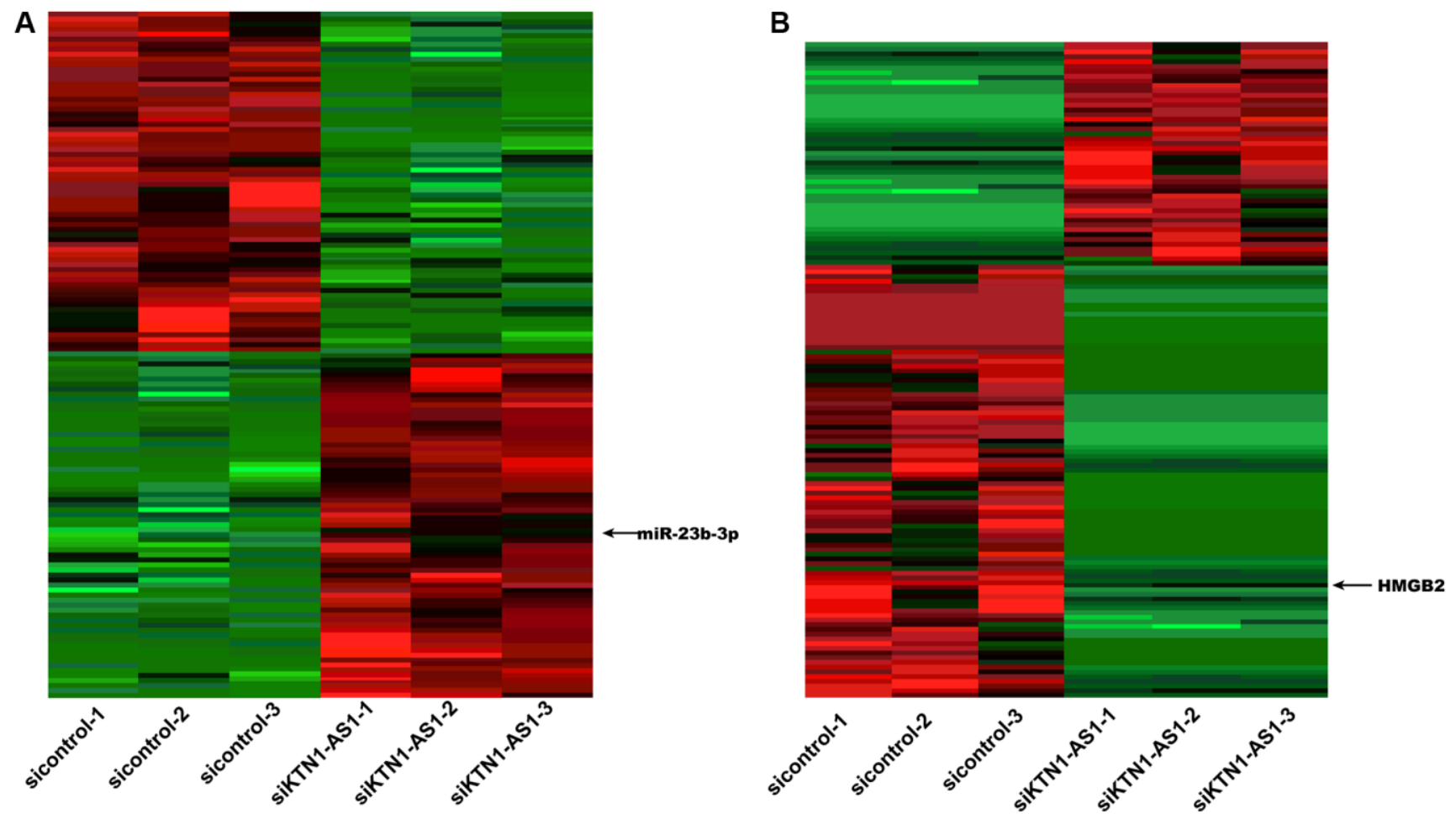

Supplementary Figure 3. The differently expressed miRNAs and genes in KTN1-AS1-depleted PC cells. (A) Heatmap of differentially expressed miRNAs in the RNA-seq analysis of PANC-1 transfected with sicontrol or sikTN1-AS1. (B) Heatmap of differentially expressed mRNAs in the RNA-seq analysis of PANC-1 transfected with sicontrol or siKTN1-AS1. fold change $\geq 2$ and $P$ value $<0.05$. 
A

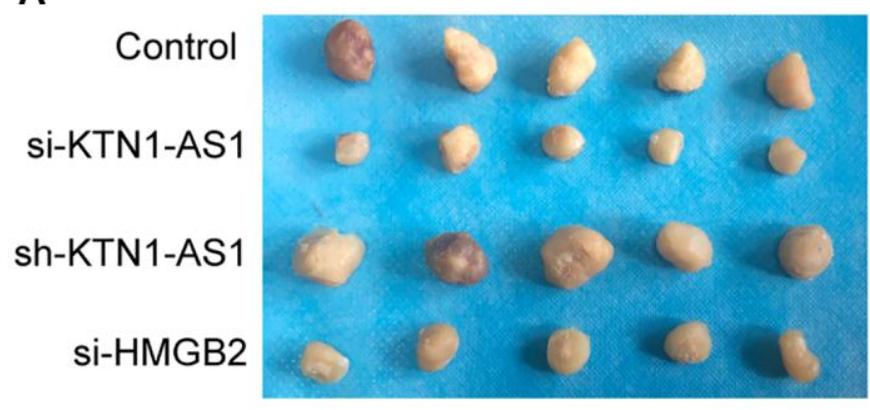

C
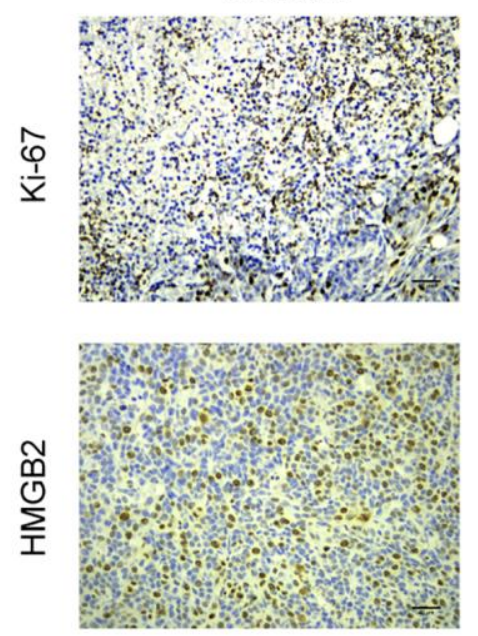

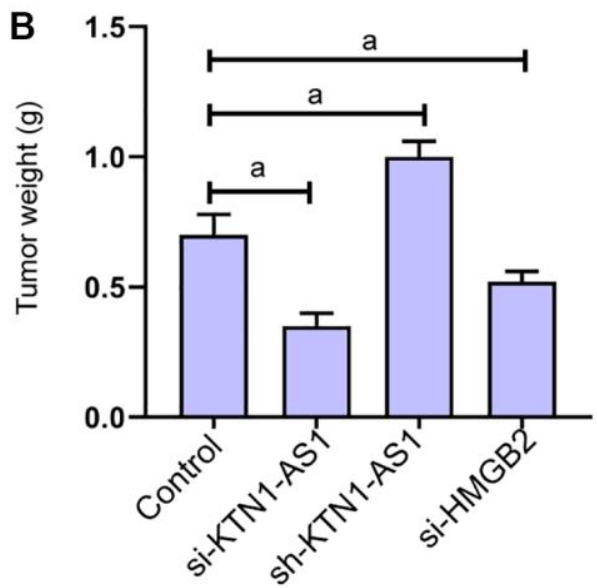

sh-KTN1-AS1
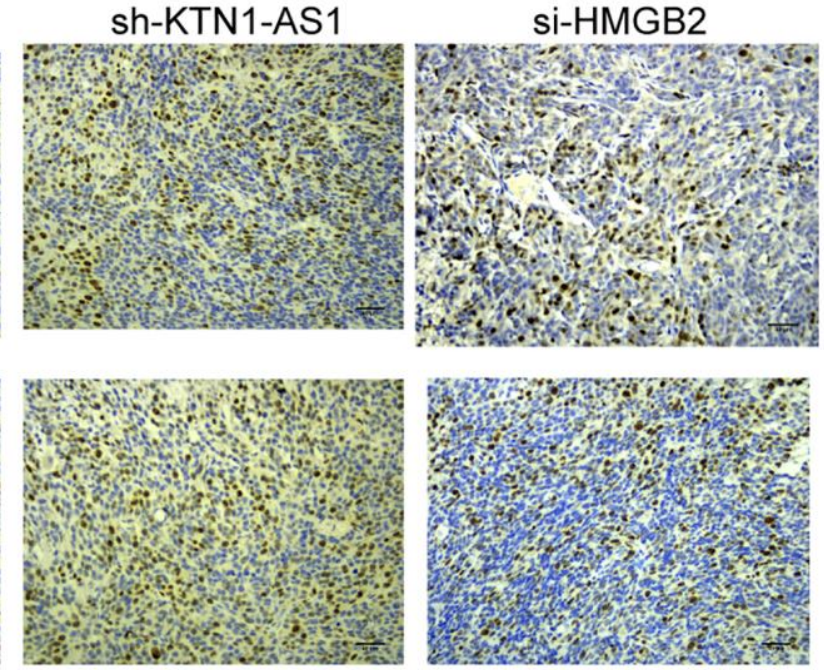

Supplementary Figure 4. The effect of KTN1-AS1 and HMGB2 on tumor formation in nude mice. (A) Changes of subcutaneous tumor size in nude mice on the 28th day. (B) Tumor weight of nude mice on the 28th day. (C) Levels of Ki-67 and HMGB2 and in nude mouse tumor. a indicates $P<0.05$. 